\title{
Robust Positioning of Laser Beams Using Proportional Integral Derivative and Based Observer-Feedback Control
}

\author{
${ }^{1}$ Kwabena A. Konadu, ${ }^{2}$ Sun Yi, ${ }^{3}$ Wonchang Choi and ${ }^{4}$ Taher Abu-Lebdeh \\ ${ }^{1} 500$ Jackson Street, Columbus, Indiana 47201-6258, USA \\ ${ }^{2}$ Department of Mechanical Engineering, \\ ${ }^{3}$ Department of Civil, Architectural and Environmental Engineering, \\ ${ }^{4}$ Department of Civil and Environmental Engineering, \\ North Carolina A\&T State University Greensboro, North Carolina, USA
}

Received 2012-10-27, Revised 2013-05-02; Accepted 2013-05-06

\begin{abstract}
High-precision positioning of laser beams has been a great challenge in industry due to inevitable existence of noise and disturbance. The work presented in this study addresses this problem by employing two different control strategies: Proportional Integral Derivative (PID) control and state feedback control with an observer. The control strategies are intended to stabilize the position of a laser beam on a Position Sensing Device (PSD) located on a Laser Beam Stabilization (or, laser beam system) system. The laser beam system consists of a laser source, a Fast Steering Mirror (FSM), a PSD and a vibrating platform to generate active disturbance. The traditional PID controller is widely used in industry due to its satisfactory performance, various available tuning methods and relatively straightforward design processes. However, design of filters to obtain the derivative signal is challenging and can unexpectedly distort the dynamics of the system being controlled. As an alternative, use of an Observer-Based State Feedback (OBSF) method is proposed and implemented. The state-space model of the laser beam system is utilized and an observer is applied to estimate the state of the system, since all the state variables cannot be measured directly. For observer design, eigenvalue assignment and optimal design methods are used and compared in terms of system performance. Also a comparative analysis between the PID and OBSF controllers is provided. Simulations and experimental results show that the OBSF controller rejects disturbance better and has a simpler design procedure.
\end{abstract}

Keywords: Laser Beams, Proportional Integral Derivative, Feedback Control, Position Sensing Device

\section{INTRODUCTION}

The term "laser" originated from an acronym for Light Amplification by Simulated Emission of Radiation. Lasers work on the principle of quantum mechanics to create a beam of light through optical amplification with all photons in a coherent state, usually with the same frequency and phase. Laser beams has a wide variety of applications, such as communication, transmitting data, printing, weapon systems, recording and various surgical and industrial applications. The requirement of high accuracy in the pointing of the laser beams poses a complicated challenge for the successful operation of these systems. This arises due to difficulty in aiming the beam on the intended target, narrow beam divergence angle and vibration of the pointing system. The work presented here intends to design controllers that correct or minimize dynamic laser beam pointing errors. The

Corresponding Author: Sun Yi, Department of Mechanical Engineering, North Carolina A\&T State University Greensboro, North Carolina, USA Tel: (336) 285-3753 Fax: (336) 334-427 
controllers are validated through simulations and experiments. The operation of the control system of a laser beam is demonstrated in Fig. 1. In operation, the beam comes from the laser source to the FSM and is reflected through a glass splitter to the target. The effect of the disturbance is normally magnified and appears on the target. The glass splitter refracts a small percentage of the beam to a position sensing device. The PSD measures the displacement of the beam from the target and sends feedback signals to the controller. The control system sends control signals to steer the FAM/actuator such that the beam remains stable on the target (PerezArancibia et al., 2009a; Bai et al., 2005; Quanser, 2010).

Techniques to address the problem using passive approach have been developed (Zia, 1992; Bodson et al., 1994; Anderson and Sarkodie-Gyan, 2004), there; both feedback and adaptive feed-forward control techniques were implemented using two actuators (a fast steering mirror and a secondary acoustic speaker located near the precision mirror) for reducing an acoustically induced jitter. Another approach is the implementation of an adaptive controller that applies Recursive Least Squares (RLS) algorithm to predict dominant output disturbance frequencies and dynamically computes control commands to minimize the output error (Arancibia et al., 2004; Chi-Ying et al., 2008; Richard et al., 2011; TsuChin et al., 2011).

A study presented in (Arnon and Kopeika, 1997) considers the implementation of passive and active vibration isolator which reduces the transmission of vibrations from the system to the target. The passive isolator reduces high frequency vibration disturbances while the active isolator dampens low-frequency, high amplitude vibrations (Baek et al., 2006; Chang and Liu, 2007). More attempts have been made to investigate the problem in (Knibbe, 1993; Perez-Arancibia et al., 2009b) by utilizing mechanical techniques for nutation. A known amount of tracking error is introduced into the system by high frequency nutation signals, which were used to determine the position of the laser beam.

An alternate approach demonstrated in (Kwabena, 2012; Landolsi et al., 2011) implements ProportionalIntegral-Derivative (PID) controllers together with a beam-stabilized optical switch to stabilize a beam at a desired angle to maximize the optical power detected by a photodiode using a voice-coil motor actuator. Such studies have showed that the proportional-integralderivative controller is an effective method of stabilizing the laser beam with minimal switching time. Proportional-integral-derivative controllers are the widely used controllers for industry applications. However, not much work has been done on stabilizing laser beams using observer-based state feedback.

The objectives are:

- To design and implement a PID controller on a laser beam stabilization equipment to stabilize the beam on a PSD

- To design an alternate controller using an observerbased state feedback method

- To compare the controllers in terms of design procedure and performance through simulations and experiments and

- To determine the most effective controller based on performance

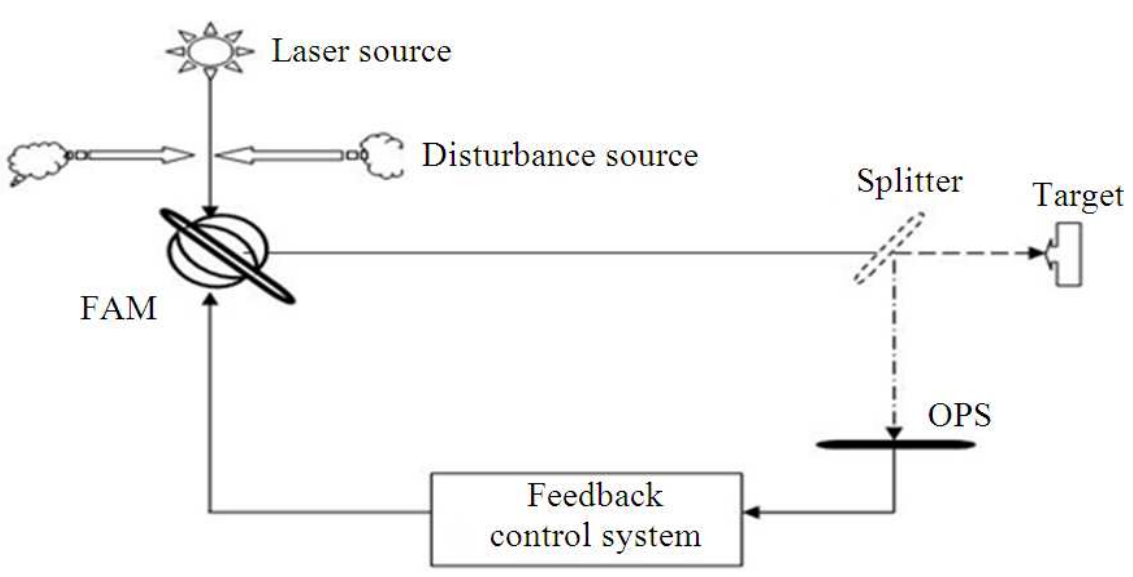

Fig. 1. Operating principle of the control system of a laser beam (Quanser, 2010) 


\subsection{Design of Proportional Integral Derivative Controller}

The purpose of this chapter is to design a proportional-integral-derivative controller Fig. $\mathbf{2}$ that uses all these three terms to compensate for any error recorded by the position sensing device on the target. This controller will determine the right amount of voltage that will steer the actuator in a way that the beam is always reflected directly to the center of the position sensing device even in active disturbance.

It is assumed that there is no actuator saturation and amplifier offset, Thus, $\mathrm{Vc}$, amp $=\mathrm{Vc}$, where $\mathrm{Vc}(s)$ is the Laplace Transform of the voice-coil digital-to-Analog voltage and $\mathrm{Vc}$, max is the maximum voltage that can be supplied to the voice-coil by the power.

The Transfer Function (T.F) of the actuator is given by Equation (1):

$$
\mathrm{P}(\mathrm{s})=\frac{\mathrm{k}}{\mathrm{s}(\tau \mathrm{s}+1)}
$$

where, $\mathrm{K}$, the open-loop steady state gain, is 2200 $\mathrm{mm} /(\mathrm{V} . \mathrm{s})$ and $\tau$, the open-loop time constant, is $0.005 \mathrm{~s}$. The Transfer Function (T.F.) of the closed loop disturbance-to-position of the system, $\mathrm{G}_{\mathrm{x}, \mathrm{d}}$, is given as (Quanser, 2010):

$$
\mathrm{G}_{\mathrm{x}, \mathrm{d}}=\frac{\mathrm{s}^{2}(\tau \mathrm{s}+1)}{\mathrm{s}^{3} \tau+\left(1 \_\mathrm{Kk}_{\mathrm{d}}\right) \mathrm{s}^{2}+\mathrm{Kk}_{\mathrm{p}} \mathrm{s}+\mathrm{Kk}_{\mathrm{i}}}
$$

where, $\mathrm{k}_{\mathrm{p}}$ is the proportional control gain, $\mathrm{k}_{\mathrm{d}}$ is the derivative control gain and $\mathrm{k}_{\mathrm{i}}$ is the integral control gain.

\subsection{Determination of the Control Gains}

For the ideal-proportional-integral-derivative gains, the denominator of Equation (2) (closed-loop T.F.) is compared with the third-order characteristic equation and obtained as Equation (3-5):

$$
\begin{aligned}
& \mathrm{k}_{\mathrm{p}}=\frac{\omega_{0}\left(\omega_{0}+2 \zeta \mathrm{p}_{0}\right) \tau}{\mathrm{K}} \\
& \mathrm{k}_{\mathrm{i}}=\frac{\omega_{0}^{2} \mathrm{p}_{0} \tau}{\mathrm{K}} \\
& \mathrm{k}_{\mathrm{d}}=\frac{2 \zeta \omega_{0} \tau+\mathrm{p}_{0} \tau-1}{\mathrm{k}}
\end{aligned}
$$

For implementation of PID controller, a filter (lowpass filter) is used to obtain the displacement of the PSD signal. The main role of the filter in the design is to remove noise from the system, since noise turns to magnify after taking the derivative of the signal.

\subsection{PID Controller}

The filter with its desired parameters is selected and the PID controller is built. The performance is analyzed to determine robustness. Figure $\mathbf{3}$ is a block diagram of the designed controller. The proportional, integral and derivative gains after applying the low-pass filter are $\mathrm{k}_{\mathrm{p}}=0.722 \mathrm{~V} / \mathrm{mm}, \mathrm{k}_{\mathrm{d}}=0.002 \mathrm{~V} . \mathrm{s} / \mathrm{mm}$ and $\mathrm{k}_{\mathrm{i}}=0.360$ $\mathrm{V} / \mathrm{mm} / \mathrm{s}$ (Kwabena, 2012) for $\omega_{0}=562.7 \mathrm{rad} / \mathrm{s}, \zeta=1$ and $\mathrm{p}_{0}=-0.5$.

The gains, $\mathrm{k}_{\mathrm{p}}, \mathrm{k}_{\mathrm{d}}$ and $\mathrm{k}_{\mathrm{i}}$ are placed in the proportional gain block, integral gain block and derivative gain block respectively as shown in Fig. 3. The low-pass filter is placed in the filter block and simulations are performed to validate the controller, before experiments are performed. The cutoff frequency, $\omega_{\mathrm{f}}$, of the 2 nd order filter is selected as $\omega_{\mathrm{f}}=\omega_{\mathrm{f}} \times 10$ and the damping ratio is 0.5 to have a phase margin larger than 75 degrees.

\subsection{Design of State Observer}

When information about the dynamics of the system is limited an observer that computes an estimate of the entire system's state vector from the output of the plant for control is used. Figure 4 shows a block diagram of the laser beam system that utilizes an observer-based state feedback for control. The plant plus the actuator intended to regulate the displacement of the laser beam is modeled in its space-vector form.

\subsection{Modeling of Beam System with the Observer}

The dynamic of the laser beam system can be modeled in its state space form as (Ogata, 2002; Franklin et al., 2008) Equation (6-7):

$$
\begin{aligned}
& \dot{\mathrm{x}}=\mathrm{Ax}+\mathrm{Bu} \\
& \mathrm{y}=\mathrm{Cx}
\end{aligned}
$$

where, $\mathrm{A}$ and $\mathrm{B}$ are system and input matrices respectively, $\mathrm{x}$ and $\mathrm{u}$ are state vectors, $\mathrm{c}$ is the output matrix (Krokavec and Filasova, 2007; Luenberger, 1964). The observer is constructed from the state space model of the laser beam system dynamics as Equation (8-9):

$$
\begin{aligned}
& \dot{\hat{x}}=A \hat{x}+B u \\
& y=c \hat{x}
\end{aligned}
$$




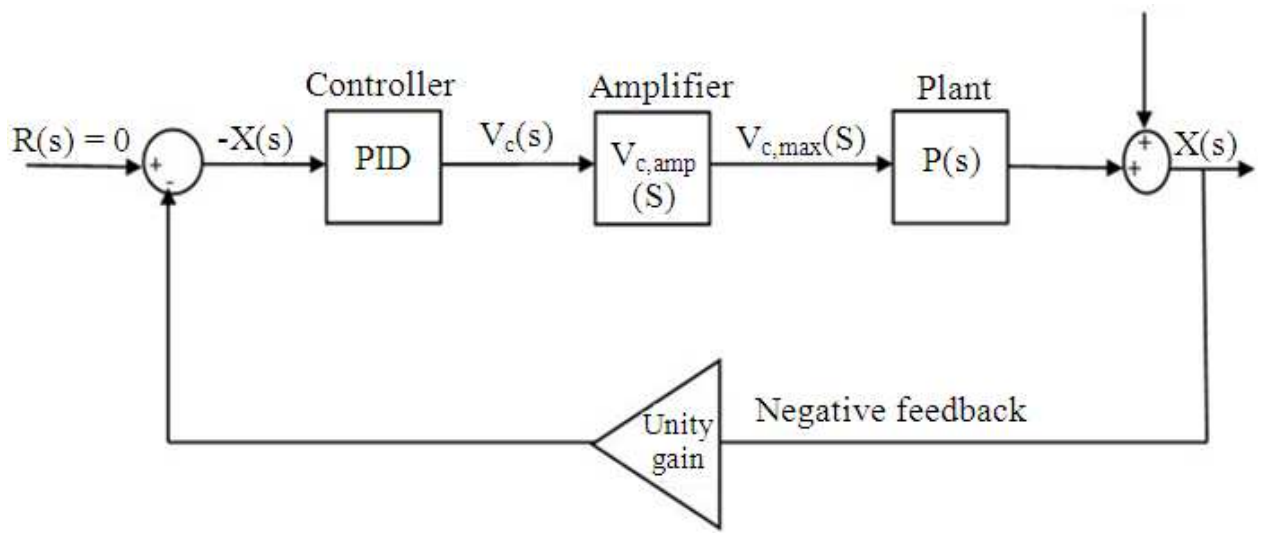

Fig. 2. Block Diagram of a PID Controller in Closed-loop

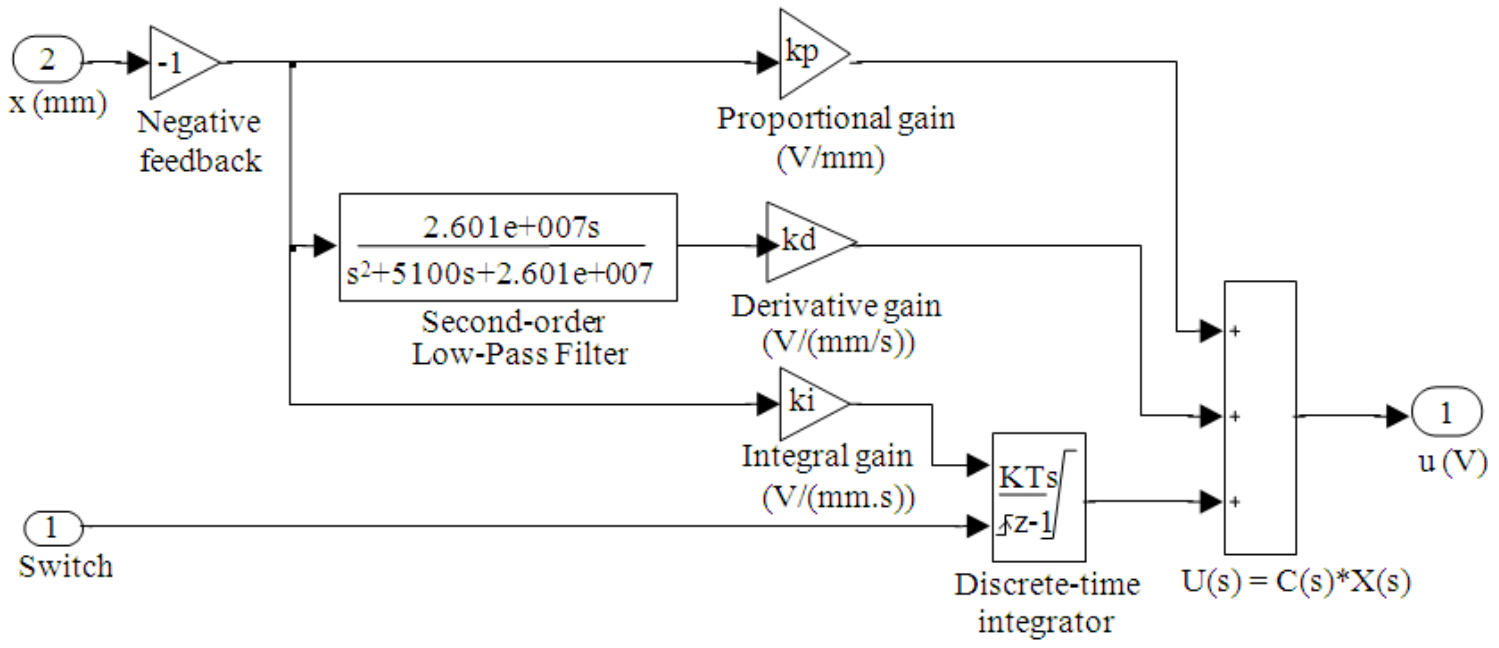

Fig. 3. Block diagram of the proportional integral derivative controller



Fig. 4. Block diagram of state feedback observer model 
where, $\hat{x}$ is the estimate of the actual state, $x$. Since the exact initial condition, $\mathrm{x}(0)$, of the laser beam system cannot be obtained the observer will be used to determine that information. The dynamics of the observer is obtained as Equation (10):

$$
\dot{\hat{x}}=A \hat{x}+B u+L(y-C \hat{x})
$$

$\mathrm{L}$, is the observer gain. Where $\mathrm{K}$, the open-loop steady state gain, is $2200 \mathrm{~mm} /(\mathrm{V} . \mathrm{s})$ and $\tau$, the open-loop time constant, is $0.005 \mathrm{~s}$ the plant transfer function for the laser beam is given by Equation (11):

$$
\frac{\mathrm{X}(\mathrm{s})}{\mathrm{V}_{\mathrm{c}}(\mathrm{s})}=\frac{2200}{\left(0.005 \mathrm{~s}^{2}+\mathrm{s}\right)}
$$

$\mathrm{X}(\mathrm{s})$, is the position measured by the position sensor and $V_{c}(s)$, is the amount of voltage that enters voice coil actuator. From the equation of motion, the system matrices are obtained as:

$$
\begin{aligned}
& \text { Systen Matrix } \mathrm{A}\left[\begin{array}{cc}
-200 & 0 \\
1 & 0
\end{array}\right] \\
& \text { Input Matrix } \mathrm{B}\left[\begin{array}{l}
1 \\
0
\end{array}\right] \\
& \text { Output Matrix } \mathrm{C}=\left[\begin{array}{ll}
0 & 440000
\end{array}\right] \\
& \text { Control Matrix } \mathrm{D}[0]
\end{aligned}
$$

Then, the equation of motion of the laser beam system in matrix vector form is Equation (12):

$$
\left[\begin{array}{l}
\dot{\mathrm{x}}_{1} \\
\dot{\mathrm{x}}_{2}
\end{array}\right]=\left[\begin{array}{cc}
-200 & 0 \\
1 & 0
\end{array}\right]\left[\begin{array}{l}
\mathrm{x}_{1} \\
\mathrm{x}_{2}
\end{array}\right]+\left[\begin{array}{l}
1 \\
0
\end{array}\right] \mathrm{U}
$$

where, $\mathrm{x}_{1}$ is the displacement and $\mathrm{x}_{2}$ is the velocity of the beam.

\subsection{System Controllability}

The controllability of the system is obtained from the state space model and used to determine if it is possible for the system to be controlled. The first step to determine if the system is controllable is to compute the controllability matrix (Chen, 1999; Haddad and Bernstein, 1992). The controllability matrix, $C_{r}$ is derived from MATLAB using the command "ctrb (A, B)". The controllability matrix is obtained as (Zhou et al., 1996):

$$
C_{r}=\left[\begin{array}{cc}
1 & -200 \\
0 & 1
\end{array}\right]
$$

Let $\mathrm{v}_{1}$ and $\mathrm{v}_{2}$ be vectors of columns 1 and 2 of matrix $\mathrm{C}_{\mathrm{r}}$ respectively. If $\alpha_{1}$ and $\alpha_{2}$ are scalar, then (Chen, 1999; Ogata, 2002; Franklin et al., 2008):

$$
\begin{aligned}
& \propto_{1} \times \mathrm{v}_{1}+\propto_{2} \times \mathrm{v}_{2}=0 \\
& \text { 1ff } \propto_{1}=\propto_{2}=0
\end{aligned}
$$

Then $v_{1}$ and $v_{2}$ are linearly independent of each other, therefore columns 1 and 2 of the controllability matrix are linearly independent. Thus the rank of the controllability matrix is 2 . Since the size of the state vector is 2 and the rank of the controllability matrix is 2 , then the system is controllable.

\subsection{System Observability}

The observability of the system is obtained from the state space model and used to determine if the state of the system can be observed if an estimator is designed. Observability matrix, $0_{\mathrm{v}}$ is obtained by using the command "obsv (A, C)" in MATLAB. The observability matrix is obtained as:

$$
0_{\mathrm{v}}=\left[\begin{array}{cc}
0 & 440000 \\
440000 & 0
\end{array}\right]
$$

The columns 1 and 2 of the matrix $0_{\mathrm{v}}$ are linearly independent. Thus the rank of the observability matrix is 2 . Since the number of rows of the state matrix is 2 and the rank of the observability matrix is 2 , then the system is observable.

\subsection{Pole Placement Design of Observer}

Pole placement is a technique assigning the locations of poles of in the closed-loop system such that desired response is achieved when control effort is applied. The location of the poles corresponds directly to the eigenvalues of the system, thus, the eigenvalues control the characteristics of the response (Ogata, 2002; Franklin et al., 2008). If the selected poles are not desirable, it will require a larger effort to control the system making the design expensive.

The pole locations of the system are obtained from the denominator of the closed-loop response equation by finding the characteristic roots or eigenvalues of the characteristic equation. The equation for the closed loop response is (Quanser, 2010) Equation (13):

$\mathrm{G}_{\mathrm{x}, \mathrm{d}}=\frac{\mathrm{s}(\tau \mathrm{s}+1)}{\mathrm{s}^{2} \tau+2 \xi \omega_{0} \tau \mathrm{s}+\omega_{0}{ }^{2} \tau}$ 
From the denominator of Equation (13) gives:

$$
\begin{aligned}
& (0.005) \mathrm{s}^{2}+(2.547) \mathrm{s}+1297.44=0 \\
& \mathrm{~s}_{1,2}=-254.7 \pm 441.15 \mathrm{i}
\end{aligned}
$$

The desired poles are obtained as:

$$
\mathrm{p}_{1}=-254.7-441.15 \mathrm{i}, \mathrm{p}_{2}=-254.7+441.15 \mathrm{i}
$$

The control gain $\mathrm{K}$, is derived from MATLAB using the Ackermann command in Equation (14):

$\mathrm{K}=\operatorname{acker}(\mathrm{A}, \mathrm{B}, \mathrm{p})$

The observer is designed to regulate the laser beam by estimating the state of the system. The estimator gain, $\mathrm{L}$, is also obtained from the Ackermann formula using the MATLAB command in Equation (15):

$L^{\prime}=\operatorname{acker}\left(A^{\prime}, C^{\prime} t\right)$

where' denotes the transpose of system matrix, A and the output matrix $\mathrm{C}$ respectively. $\mathrm{t}$ is the desired observer pole location. For a faster decay of the estimator error, the desired estimator Pole location $t$, is chosen by a factor of 5 (Ogata, 2002; Franklin et al., 2008; Zhou et al., 1996):

$$
\mathrm{t}_{1}=-1273.5-2205.8 \mathrm{i}, \mathrm{t}_{2}=-1273.5+2205.8 \mathrm{i}
$$

The resulting observer gain, $\mathrm{L}$ is:

$$
L=\left[\begin{array}{l}
13.677 \\
-0.005
\end{array}\right]
$$

\subsection{Optimal Design of Robust Observer}

The design of the observer using the Ackerman formula does not provide robust estimation in the presence of noise in the system. Observer design through the Ackerman formula can make the estimator unstable and inaccurate because it does not recognize the disturbance from the process and noise from the sensor. Thus, the estimated state will diverge from the real state if disturbance and noise is introduced into the system (Ogata, 2002; Franklin et al., 2008; Zhou et al., 1996).

The Kalman technique is used to design a robust state estimator to generate optimal estimates of the state of the system. The Kalman takes the state-space model of the system where not all outputs are available for measurement and considers all other inputs (noise) as stochastic as shown in Fig. 5. The method uses known input $\mathrm{u}$ and covariance matrices $\mathrm{Qn}, \mathrm{Nn}$ and $\mathrm{Rn}$ from the process disturbance $\mathrm{w}$ and measurement noise, $\mathrm{v}$ to compute the optimal estimator gain $\mathrm{L}$. The covariance matrices are:

$$
\mathrm{Qn}=\mathrm{E}\left\{\mathrm{ww}^{\prime}\right\}, \mathrm{Rn}=\mathrm{E}\left\{\mathrm{vv}^{\prime}\right\} \text { and } \mathrm{Nn}=\mathrm{E}\left\{\mathrm{wv}^{\prime}\right\}
$$

where, $\mathrm{w}$ and $\mathrm{w}$ ' are the process disturbance vectors and its transpose respectively, while $\mathrm{v}$ and v' denote the sensor noise vector and its transpose. This system is assumed to be corrupted by noise (Zhou et al., 1996; Skogestad and Postlethwaite, 1996) Equation (16 and 17):

$$
\begin{aligned}
& \dot{\mathrm{x}}=\mathrm{Ax}+\mathrm{Bu}+\mathrm{w} \\
& \mathrm{y}=\mathrm{cx}+\mathrm{v}
\end{aligned}
$$

The dynamics of the observer with the error in estimation is given by Equation (18):

$$
\begin{aligned}
& \dot{\mathrm{e}}=A x+B u+w-A \hat{x}-B u-L(C x+v-C \hat{x}) \\
& \dot{\mathrm{e}}=(A-L C) e+w-L v
\end{aligned}
$$

Due to the introduction of process and measurement noise into the system, the difference between the real state variable and the estimated state variable will not be minimized to zero. Thus, the error will not approach zero asymptotically, $\hat{\mathrm{x}}$ grows further apart from $x$. In order to ensure that the effect of this error and disturbance on the target remains minimized as possible, the optimal linear quadratic estimator LQE technique using the Kalman filter is used to choose the optimal estimator gain, $\mathrm{L}$.

The optimal observer gain which minimizes this error caused by the process disturbance and measurement noise is Equation (19):

$\mathrm{L}=\mathrm{PC} \times \mathrm{V}^{-1}$

where, $\mathrm{p}$ is the solution of the Algebraic Ricatti Equation (ARE):

$$
\mathrm{PA}+\mathrm{AP}-\mathrm{PC} \times \mathrm{V}^{-1} \mathrm{CP}+\mathrm{W}=0
$$

$\mathrm{p}$, should be a unique positive semi-definite solution of Equation (20) ARE. C, is the output matrix of the laser beam system, $\mathrm{w}$ and $\mathrm{v}$ are the disturbance and noise matrix respectively. The optimal choice of $\mathrm{L}$, Kalman filter gain is obtained from MATLAB by the command Equation (21):

$[$ kest, $\mathrm{L}, \mathrm{P}]=\operatorname{kalman}(\mathrm{sys}, \mathrm{Qn}, \mathrm{Rn}, \mathrm{Nn})$ 


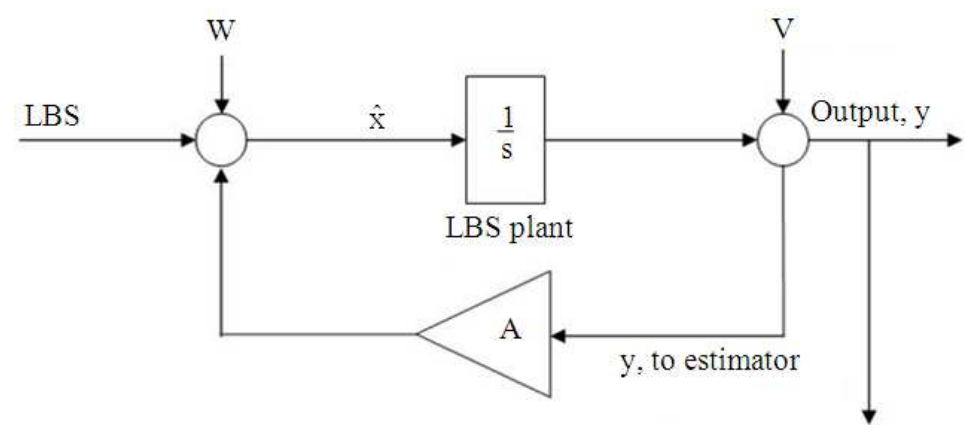

Fig. 5. Diagram showing introduction of noise and disturbance on LBS

The optimal observer gain, $\mathrm{L}$ is:

$$
L=\left[\begin{array}{l}
5.6529 \\
0.0051
\end{array}\right]
$$

The solution to the ARE is:

$$
\mathrm{p}=10^{-3} \times\left[\begin{array}{cc}
0.7025 & 0.0003 \\
0.0003 & 0.00001
\end{array}\right]
$$

\subsection{State Observer}

Figure 6 is a block diagram of the laser beam system with an observer. Simulations are performed to verify the response of the controller. The observer gain, L and control gain, $\mathrm{K}$, obtained are placed in the observer gain block and control block to test the controller through simulations before experiments are performed.

The available output, displacement, is measured by the position sensing device as $\mathrm{X}(\mathrm{mm})$. The observer continuously estimates the state of the system based on the output (X) from the PSD. Other output parameters like velocity and acceleration can be obtained from the estimator. This estimatator output is Uc, in the form of voltage. The diagram shows block locations for the observer gain L, control gain U. System matrix (A), input matrix (B) and output matrix (C).

\subsection{Experimental SET-UP}

The experimental set-up shown in Fig. 7 and 8 consist of four main components: PC, laser beam stabilization component, Quanser Personality Intelligent Data (QPID) acquisition board and a Peripheral Component Interconnect (PCI) express board. These are inter-connected and act as a Hardware-In-the-Loop (HIL). The PCI board is inserted into the CPU and connected to the QPID terminal board through analog cables. The terminal board is then connected to the laser beam stabilization component through analog and encoder cables before the system is powered. Experiments are run on this system by generating realtime codes from models that runs on a real-time kernel of the processor of the PC. After designing the appropriate controller, the design is built and tested through simulations on the computer.

The laser beam stabilization component in Fig. 7 consists of a stationary laser source for providing the laser beam, a FSM which acts as an actuator mounted on a vibrating platform, a DC motor for subjecting the platform to active disturbance and an amplifier. The amplifier makes sure that the voltage or maximum power that is being supplied to the actuator by the Digital-toAnalog convertor (D/A) is not exceeded and it also magnifies the signal from the position sensing device to the Analog-to-Digital converter. The QPID acts as a data acquisition board and also acts as a Digital-to-Analog-toDigital convertor (D-A-D), thus it digitizes the analog position signal of the laser beam measured by the position sensor for the computer and also converts digitized control signal from the computer to analog form for the actuator. Controllers intended to stabilize the vibrations induced into the beam using the FSM and feedback from the position sensor are designed.

The laser beam is subjected to active disturbance by increasing the disturbance voltage; this causes an offset load attached at the end the D.C motor to revolve producing a back and forth sliding motion, thereby inducing vibrations into system. The controller intended to stabilize the system is switched on and the response is analyzed.

\subsection{Simulation Set-Up}

To prevent any damages to the laser beam stabilization equipment, simulations are performed to validate the design before implementation. Figure 9 is a block diagram of the experimental set-up to test the controllers through simulation (Chua et al., 2007). 
Kwabena A. Konadu et al. / American Journal of Applied Sciences, 10 (4): 374-387, 2013



Fig. 6. Block diagram of the OBSF controller

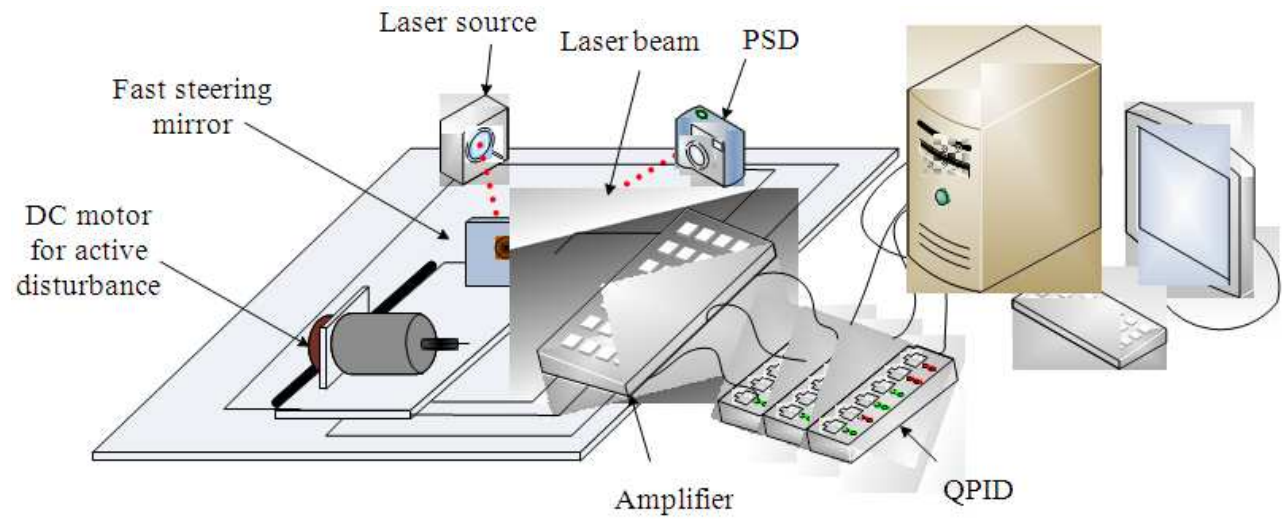

Fig. 7. Schematic diagram of a laser beam stabilization experimental set-up

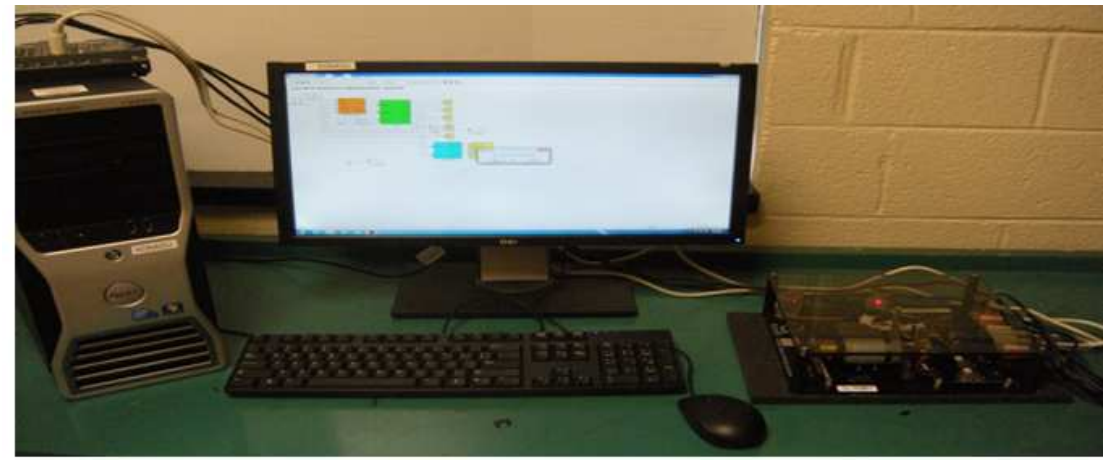

Fig. 8. Experimental set-up of the laser beam system 




Fig. 9. Block diagram of experimental setup

This block diagram consist of four main blocks; (1) the Control System block, which contains the controller, (2) the Signal Generator block which subjects the system to active disturbance by regulating the frequency and amplitude of the input signal, (3) Plant, is the actuator of the system and (4) the Scope is the position sensor for detecting the position of the laser beam.

\section{DISCUSSION}

\subsection{Simulation and Experimental Results}

The response of the system employing the PID and observer-based state feedback controllers respectively for an input sine signal of $12 \mathrm{~Hz}$ frequency and $1 \mathrm{~mm}$ amplitude is shown in Fig. 10 and 11, respectively. A comparison of simulation response of the controllers in closed-loop is shown in Fig. 12. In closed-loop, the response of the observer-based state feedback controller shows that the high amplitude vibration of the laser beam reduced to an amplitude of $2 \mathrm{~mm}$ while for the PID controller, the amplitude of the laser beam decreases to about $1.7 \mathrm{~mm}$.

Both controllers proved to be stable and effective in eliminating the $12 \mathrm{~Hz}$ disturbance and significantly rejecting the $350 \mathrm{~mm}$ amplitude and stabilizing the vibration of the laser beam. However, the proportional-integral-derivative controller sustains a relatively smaller amplitude. The results for both controllers are considered satisfactory shown in Fig. 12, therefore the peformance of the controllers are tested experimentally on the actual laser beam system.

Figure 13 is a plot of experimental response of the PID in open-loop that is switched to closed-loop after
$11.5 \mathrm{sec}$. From observation, the beam is displaced from the reference point immediately when the controller is switched from open-loop to closed-loop. This offset however decreases linearly over time and gradually approaches steady state at zero.

Experimental response of the observer-based state feedback controller and robust is shown in Fig. 14 and 15, respectively. From observation, the laser beam oscillation stabilizes on the position sensing device after switching to closed-loop with a $12 \mathrm{~Hz}$ input disturbance frequency. In open-loop the laser beam vibrates with an amplitude of approximately $0.7 \mathrm{~mm}$; however, this vibration minimizes to an amplitude of approximately $0.01 \mathrm{~mm}$ at steady-state.

The response of the robust observer in Fig. 15 is similar to the observer-based state feedback controller in Fig. 14 because the experiment was peformed under well regulated conditions and the amount of lighting in the room was controlled.

Comparisons between the controllers are made to investigate the method that best regulates the laser beam, in terms of rejecting oscillations in the laser beam. Figure 16 is a comparison of the experimental response of the controllers. Comparison of system gain for the controllers is at Fig. 17 and Table 1 describes the differences in the controllers.

After experimental implementation of all three controllers, the gains of the closed loop system are compared. The closed-loop gains are observed for a series of different disturbance frequencies. The lower the system gain, the more efficient the controller is in rejecting disturbance. For all three controllers, the system maintains a gain below 0.05 for a range of disturbance frequencies as evident in Fig. 17. 
Kwabena A. Konadu et al. / American Journal of Applied Sciences, 10 (4): 374-387, 2013

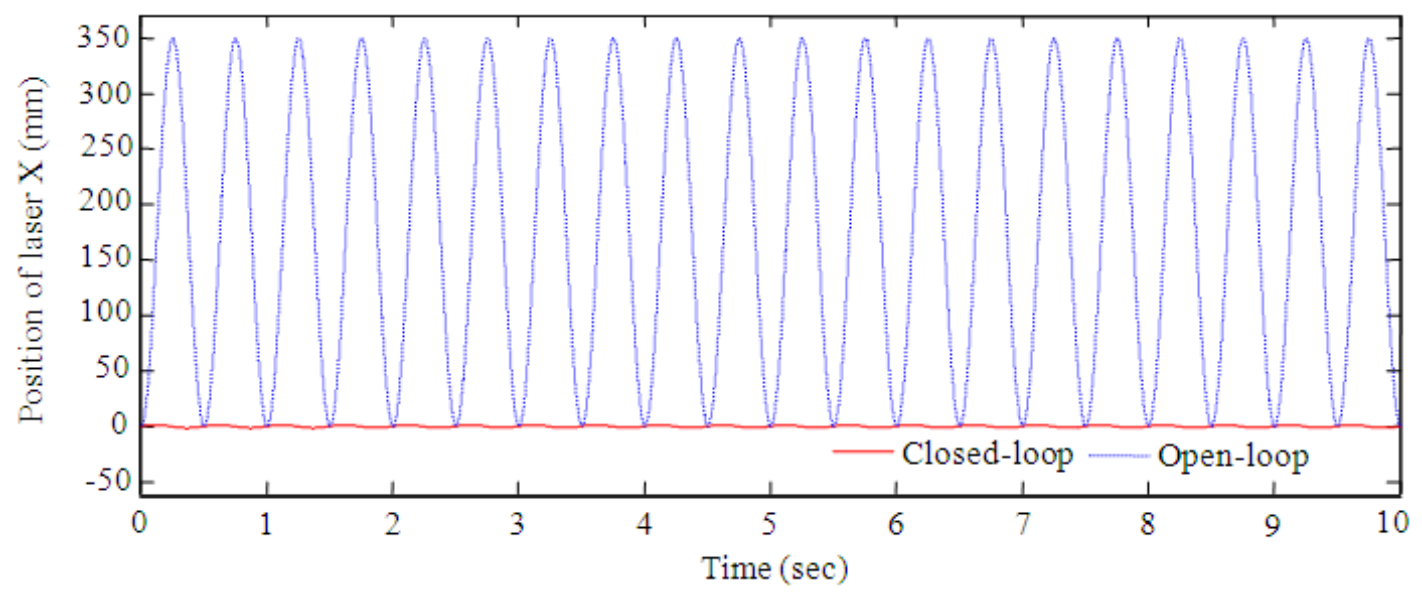

Fig. 10. Simulation response of PID controller

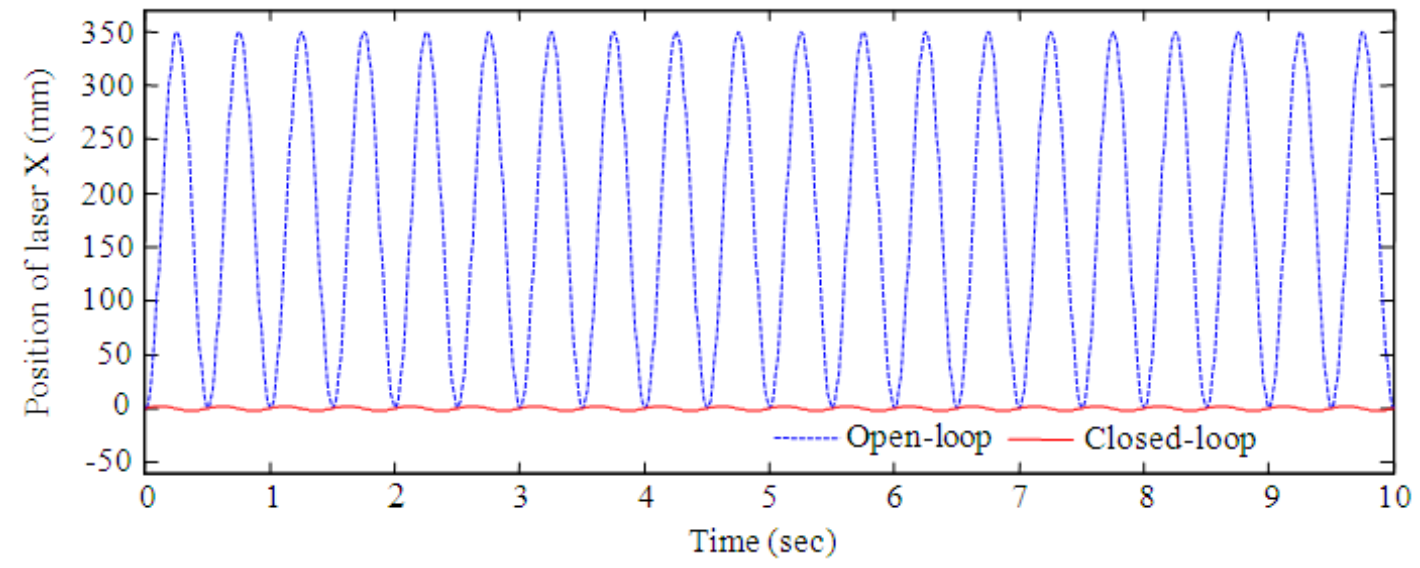

Fig. 11. Simulation response of OBSF controller

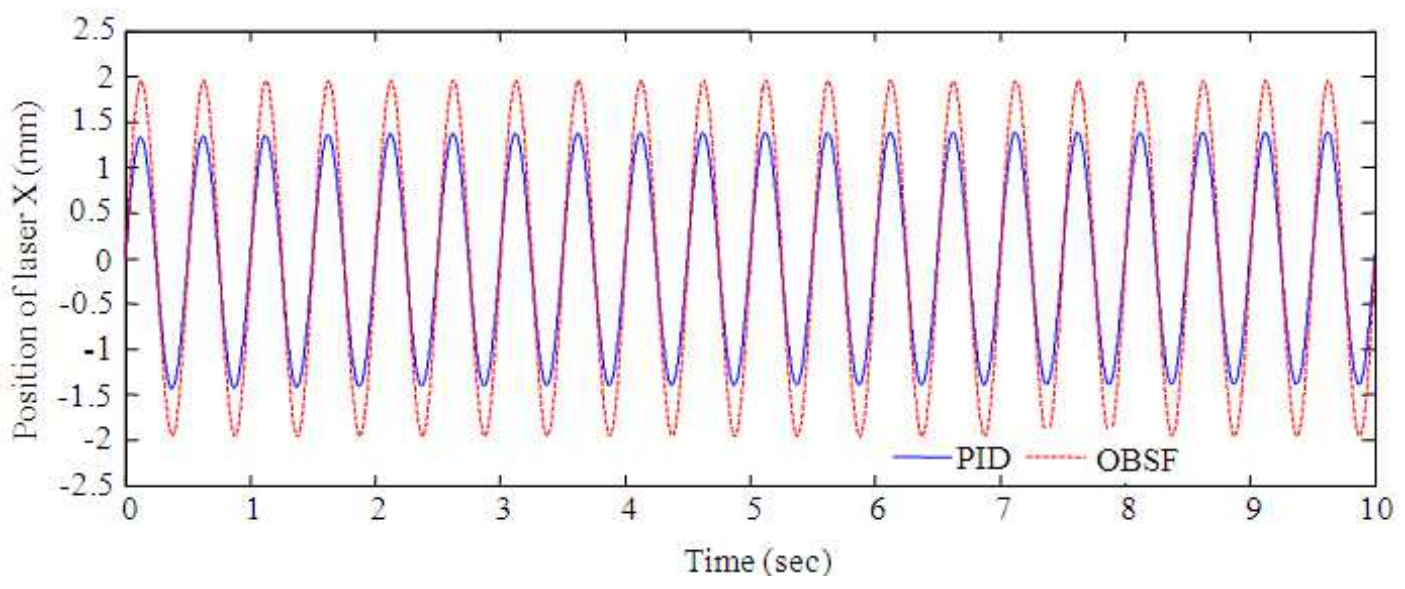

Fig. 12. Comparison of closed-loop simulation responses 
Kwabena A. Konadu et al. / American Journal of Applied Sciences, 10 (4): 374-387, 2013

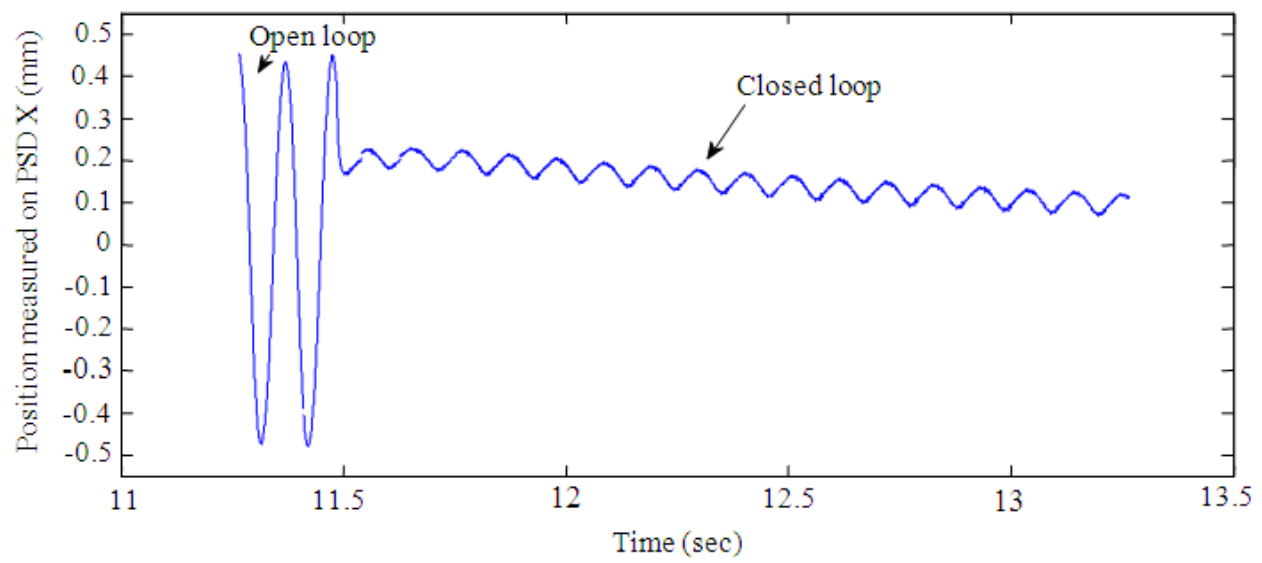

Fig. 13. Experimental response of PID controller



Fig. 14. Experimental response of OBSF controller

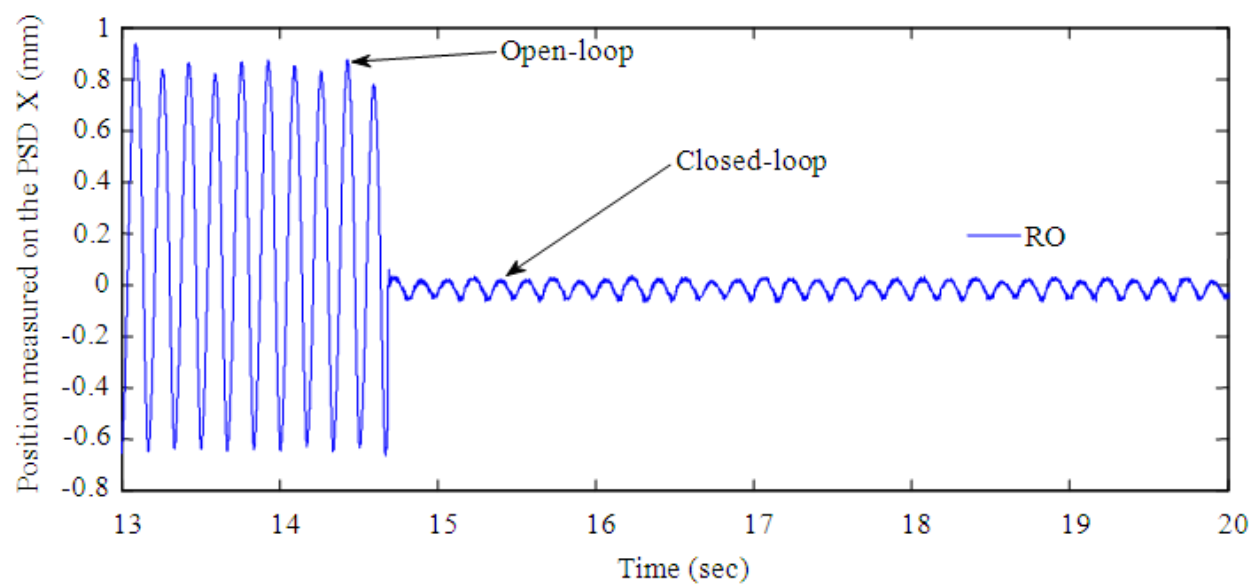

Fig. 15. Experimental response of robust observer 




Fig. 16. Comparison of experimental response of controllers

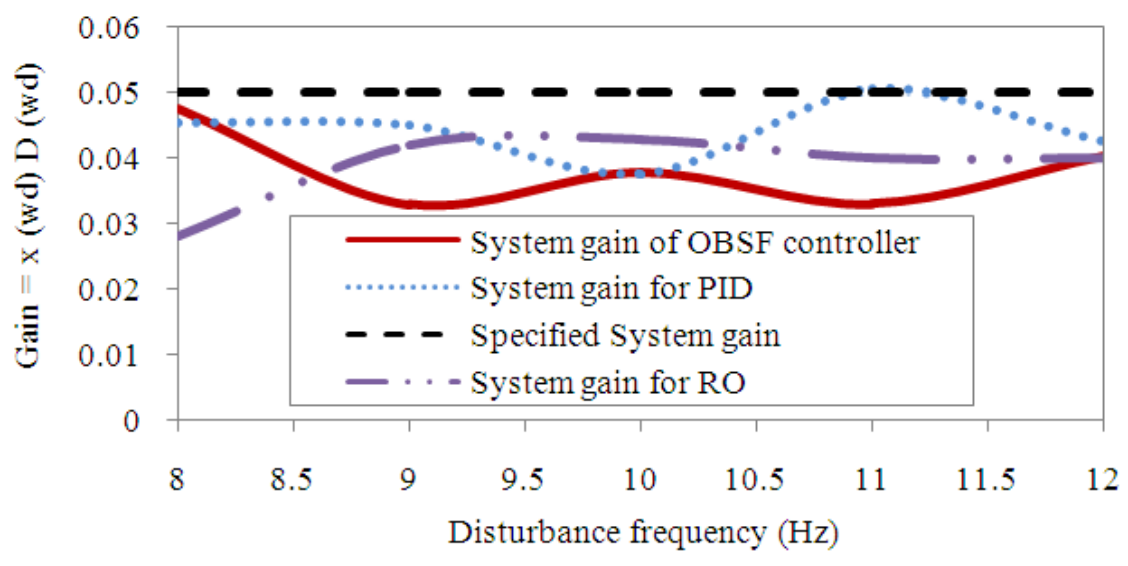

Fig. 17. Comparison of System Performance for Controllers

Table 1. Observed comparison of controllers

\begin{tabular}{|c|c|c|}
\hline $\begin{array}{l}\text { Character- } \\
\text { Istics }\end{array}$ & $\begin{array}{l}\text { State } \\
\text { feedback }\end{array}$ & $\begin{array}{l}\text { Proportional } \\
\text { integral derivative }\end{array}$ \\
\hline Settling time & $\begin{array}{l}\text { Quicker convergence, achieves } \\
\text { steady state very fast }\end{array}$ & $\begin{array}{l}\text { Slow convergence, achieves } \\
\text { steady state at a slow rate }\end{array}$ \\
\hline $\begin{array}{l}\text { Accuracy and } \\
\text { stability }\end{array}$ & $\begin{array}{l}\text { No filter is required. One does } \\
\text { not need to obtain the signal. } \\
\text { for D action in proportional integral derivative controller }\end{array}$ & $\begin{array}{l}\text { A filter is required when taking the } \\
\text { derivative of the signal to be } \\
\text { multiplied with } \mathrm{k}_{\mathrm{d}} \text {. }\end{array}$ \\
\hline $\begin{array}{l}\text { Design } \\
\text { procedure }\end{array}$ & $\begin{array}{l}\text { Compact form, since the model } \\
\text { is expressed in } \\
\text { matrix-vector form, the calculation } \\
\text { is friendly. Calculation of control gains is MATLAB-friendly. }\end{array}$ & $\begin{array}{l}\text { Design of control requires a } \\
\text { relatively complicated process. It } \\
\text { handles scalar multi-variable models, } \\
\text { and requires designing extra filters for tuning }\end{array}$ \\
\hline Robustness & $\begin{array}{l}\text { Handles uncertainty like process disturbance and } \\
\text { measurement noise in a relatively simple way }\end{array}$ & A bit cumbersome in handling noise \\
\hline
\end{tabular}




\section{CONCLUSION}

This study presented the design of a PID controller that uses the feedback signal from a position sensing device to regulate a voice-coil actuator. The controller has been designed to stabilize a laser beam such that the incident laser beam on the FSM is reflected to the middle of the position sensor even in the presence of noise and active disturbance. An alternate observer-based state feedback scheme for controlling the laser beam system has been proposed. This controller models the laser beam system as a linear time-invariant plant and estimates the state of the plant by stabilizing the beam at all conditions.

A comparison has been made to investigate the appropriate and effective control method based on design procedure and performance. Simulation results demonstrate that both controllers are effective and suitable for eliminating vibrations and stabilizing the laser beam on the PSD. The observer-based state feedback controller is relatively simple and the design is straight forward if the model and state of the system can be obtained while the design process for the PID controller is relatively complicated due to the design of filters, which alters the dynamic of the system.

\section{REFERENCES}

Anderson, J. and T. Sarkodie-Gyan, 2004. Mechanical design and modeling of an inertial reference unit for laser beam stabilization. Proceedings of the World Automation Congress, Jun. 28-Jul. 1, IEEE Xplore Press, Seville, pp: 389-396.

Arancibia, N.O.P., S. Gibson and T.C. Tsao, 2004. Adaptive control of mems mirrors for beam steering. Proceedings of the ASME International Mechanical Engineering Congress and Exposition, (IMECE '04), American Society of Mechanical Engineers, pp: 71-80.

Arnon, S. and N.S. Kopeika, 1997. Laser satellite communication network-vibration effect and possible solutions. IEEE Proc., 85: 1646-1661. DOI: 10.1109/5.640772

Baek, J.S., C.C. Chung and M. Tomizuka, 2006. Antishock controller design for optical disk drive systems with a nonlinear controller. Proceedigns of the American Control Conference, Jun. 14-16, IEEE Xplore Press, Minneapolis, MN, pp: 8. DOI: 10.1109/ACC.2006.1656511
Bai, Y., H. Zhuang and Z.S. Roth, 2005. Fuzzy logic control to suppress noises and coupling effects in a laser tracking system. IEEE Trans. Control Syst. Technol., 13: 113-121. DOI: 10.1109/TCST.2004.833653

Bodson, M., A. Sacks and P. Khosla, 1994. Harmonic generation in adaptive feedforward cancellation schemes. IEEE Trans. Automat. Control, 39: 19391944. DOI: $10.1109 / 9.317130$

Chang, C.S. and T.S. Liu, 2007. LQG controller for active vibration absorber in optical disk drive. IEEE Trans. Magn., 43: 799-801. DOI: 10.1109/TMAG.2006.888417

Chen, C.T., 1999. Linear System Theory and Design. 3rd Edn., Oxford University Press, New York, ISB-10: 0195117778, pp: 334.

Chi-Ying, L., C. Yen-Cheng, T. Tsu-Chin and S. Gibson, 2008. Laser beam tracking by repetitive and variable-order adaptive control. Proceeidngs of the American Control Conference, Jun. 11-13, IEEE Xplore Press, Seattle, WA., pp: 2371-2376. DOI: 10.1109/ACC.2008.4586846

Chua, G.H., T. Rainsford, W.K. Tan and I. Linke, 2007. Dynamic laser beam stabilization for terahertz systems. Proceedings of the Photonics: Design, Technology and Packaging III, Dec. 5-7, SPIE, Canberra, ACT, Australia. DOI: 10.1117/12.758730

Franklin, G.F., J.D. Powell and A. Emami-Naeini, 2008. Feedback Control of Dynamic Systems. 5th Edn., Pearson Education India, New Delhi, ISBN-10: 8131721426, pp: 958.

Haddad, W.M. and D.S. Bernstein, 1992. Controller design with regional pole constraints. IEEE Trans. Automat. Control, 37: 54-69. DOI: 10.1109/9.109638

Knibbe, T.E., 1993. Spatial tracking using an electrooptic nutator and a single-mode optical fiber. M.S. Thesis, Massachusetts Institute of Technology, Massachusetts.

Krokavec, D. and A. Filasova, 2007. Pole assignment in robust state observer design. J. PLUS, 2: 75-78.

Kwabena, A.K., 2012. Design of robust feedback controllers for a laser beam stabilizer. M.S. Thesis, North Carolina Agricultural and Technical State University.

Landolsi, T., R. Dhaouadi and O. Aldabbas, 2011. Beamstabilized optical switch using a voice-coil motor actuator. J. Franklin Inst., 348: 1-11. DOI: 10.1016/j.jfranklin.2009.02.004 
Luenberger, D.G., 1964. Observing the state of a linear system. IEEE Trans. Military Electron., 8: 74-80. DOI: 10.1109/TME.1964.4323124

Ogata, K., 2002. Modern Control Engineering. 4th Edn., Prentice Hall PTR, Upper Saddle River, ISBN-10: 0130609072, pp: 964.

Perez-Arancibia, N.O., J.S. Gibson and T. Tsu-Chin, 2009a. Frequency-weighted minimum-variance adaptive control of laser beam jitter. IEEE/ASME Trans. Mechatron., 14: 337-348. DOI: 10.1109/TMECH.2009.2017532

Perez-Arancibia, N.O., J.S. Gibson and T.C. Tsao, $2009 \mathrm{~b}$. Laser beam pointing and stabilization by intensity feedback control. Proceedings of the American Control Conference, Jun. 10-12, IEEE Xplore Press, St. Louis, MO, pp: 2837-2842. DOI: 10.1109/ACC.2009.5160679

Quanser, 2010. Laser beam stabilization instructor manual. Quanser Speciality Experiment Series: LBS Laboratory Workbook.
Richard, T., J. O'Brien and R.J. Watkins, 2011. Adaptive $\mathrm{H} \infty$ vibration control. Proceedings of the Dynamic Systems and Control Conference and Bath/ASME Symposium on Fluid Power and Motion Control, Oct. 31-Nov. 2, ASME, Arlington, Virginia, USA., pp: 181-188. DOI: 10.1115/DSCC2011-5949

Skogestad, S. and I. Postlethwaite, 1996. Multivariable Feedback Control: Analysis and Design. 1st Edn., Wiley, Chichester, ISBN-10: 0471942774, pp: 559.

Tsu-Chin, T., S. Gibson, K.C. Chiu and C. Shean-Jen, 2011. Adaptive control for focusing of optical drive $\mathrm{read} / \mathrm{write}$ heads. Proceedings of the American Control Conference, Jul. 29-Jul. 1, IEEE Xplore Press, San Francisco, CA., pp: 588-593.

Zhou, K., J.C. Doyle and K. Glover, 1996. Robust and Optimal Control. 1st End., Prentice Hall PTR, Kemin Zhou, ISBN-10: 0134565673, pp: 596.

Zia, O., 1992. On the control aspect of laser frequency stabilization. Proceedings of the American Control Conference, (ACC' 92), American Automatic Control Council, pp: 1628-1629. 